MOHAMMAD ALI SAHRAEI, Ph.D. ${ }^{1,2}$

E-mail: ali.sahraei@erzurum.edu.tr

EMRE KUSKAPAN ${ }^{1}$

E-mail: emre.kuskapan@erzurum.edu.tr

MUHAMMED YASIN ÇODUR, Ph.D. ${ }^{1}$

(Corresponding author)

E-mail: mycodur@erzurum.edu.tr

${ }^{1}$ Erzurum Technical University

Faculty of Engineering and Architecture

Civil Engineering Department

25200, Erzurum, Turkey

${ }^{2}$ Civil Engineering Department, Faculty of Engineering

Girne American University, Girne

N. Cyprus Via Mersin 10, Turkey
Traffic and Environment (Ecology) Original Scientific Paper Submitted: 15 Sep. 2020 Accepted: 3 Dec. 2020

\title{
IMPACT OF COVID-19 ON PUBLIC TRANSPORTATION USAGE AND AMBIENT AIR QUALITY IN TURKEY
}

\begin{abstract}
COVID-19 caused by the SARS-CoV-2 virus is a global health concern due to the quick spread of the disease. In Turkey, the first confirmed COVID-19 case and death occurred on 11 and 15 March 2020, respectively. There is a lack of research on the impact of COVID-19 on public transportation mobility and the Air Quality Index (AQI) around the world. The objective of this research is to consider the impact of COVID-19 on public transportation usage and consequently the AQI level in Turkey. Data collection for the analysis of public transportation usage and the air quality status during pre-lockdown and lockdown was carried out using the public transportation applications Moovit and World's Air Pollution. The results demonstrated that during the lockdown in Ankara and Istanbul, public transportation usage dramatically decreased by more than $80 \%$ by the end of March and did not change significantly until the end of May. As regards air quality, the results confirmed that air quality improved significantly during the lockdown. For Ankara and Istanbul, the improvement was estimated at about $9 \%$ and $47 \%$, respectively.
\end{abstract}

\section{KEYWORDS}

COVID-19; public transportation; Air Quality Index; Turkey; lockdown.

\section{INTRODUCTION}

From December 2019 in Wuhan, China, the ongoing COVID-19 outbreak has been spreading rapidly across many countries, with Italy, Spain, France, the United Kingdom, and China being the hardest hit. As of mid-April 2020, more than 2.3 million cases of this disease were recognized and verified in more than 200 countries. To control the spread of COVID-19 from the outset, a number of measures have been taken in several countries, including travel restrictions, which proved to be one of the most efficient responses in many countries. In response to the outbreak, the Chinese government imposed a lockdown in Wuhan, which was known as the greatest attempt to save human beings in history. These travel restrictions have since considerably mitigated the spread of COVID-19 [1, 2].

In the second week of March 2020, it was confirmed that COVID-19 had reached Turkey. The first death due to the coronavirus in Turkey occurred on $15 \mathrm{March}$, and it was proven that the coronavirus had spread almost throughout the entire country. On 14 April, the Turkish government announced that the spread of COVID-19 reached its peak in Turkey in the fourth week and began to slow down [3]. As of 31 May 2020, the total number of confirmed cases in Turkey was over 163,942, of which 144,598 have recovered, and 4,540 passed away. Although Turkey also surpassed China in terms of the total number of confirmed cases on 20 April, the rapid increase in the number of confirmed cases in Turkey did not overburden the public healthcare system, and the initial case-fatality rate remained lower compared to European countries such as Germany, Spain, Italy, United Kingdom (UK), and Sweden [4].

In the light of the public transportation performance in the world as well as concerning the repercussions of COVID-19 on the transportation sector and mobility, most research has focused on the in- 
fluence of the global mobility on China and its impact on the spread of the coronavirus in that country [5-8]. A study conducted by Aloi [9] suggests that incomplete information, news, research, etc., occur in places where little research on the decrease in mobility has been carried out, because of social distancing measures and the decrease in travel. Wuhan, China, was the first to suspend all modes of public transportation. It was a substantial effort to halt the spread of the coronavirus, which may be transmitted from person to person. This was simply because restricting transport would reduce the chance of the virus reaching other urban areas in China and other countries around the world. This was happening at a time when millions of Chinese were traveling across the country for the week-long vacation that was Chinese New Year.

Urban air pollution (UAP) is a major issue worldwide, both in developing and developed countries. Increasing urban population and a higher number of automobiles in cities must lead to serious air pollution which affects human health and the environment. The World Health Organization (WHO) has estimated that the increasing UAP will lead to more than 2 million fatalities per year in developing countries, along with numerous cases of respiratory issues $[10,11]$. The WHO also noted that in addition to the road transport sector, industrial and commercial activities also lead to UAP. More than $70-80 \%$ of air pollution in big cities in developing countries is attributed to vehicular emissions generated by a large number of older automobiles as well as poor automobile maintenance, insufficient highway infrastructure, and low fuel quality $[12,13]$. The criteria pollutants responsible for deteriorating urban air quality are generally sulfur dioxide $\left(\mathrm{SO}_{2}\right)$, oxides of nitrogen $\left(\mathrm{NO}_{\mathrm{x}}\right)$, particulate matter $(\mathrm{PM})$, and carbon monoxide (CO) [14].

Climate specialists predict that greenhouse gas (GHG) emissions could fall to levels not seen since World War II. This result is mainly due to the social distancing guidelines imposed by the authorities after the occurrence of the coronavirus. For instance, in Wuhan, China, strong social distancing measures have been applied since the end of 2019 . Consequently, industrial facilities and power plants ceased their production. Additionally, the use of automobiles declined significantly. All this led to a remarkable decrease in the levels of PM and nitrogen dioxide $\left(\mathrm{NO}_{2}\right)$, which have a size of less than 2.5 $\mu \mathrm{m}$ (PM2.5) [15, 16].
In general, there is a lack of research on the impact of COVID-19 on public transportation mobility and UAP around the world. The objective of this research is to consider the impact of COVID-19 on public transportation usage and consequently the level of the Air Quality Index (AQI) in Turkey. This paper is organized as follows. Section 2 provides a literature review related to the existing research on public transportation usage and the AQI during COVID-19. In section 3, the methodology for the calculation and analysis of the AQI is presented. Section 4 presents the results and the discussion to demonstrate the objectives. Concluding statements are provided in Section 5.

\section{LITERATURE REVIEW}

Motor vehicles such as public transportation generate various forms of air pollutants, most notably $\mathrm{CO}, \mathrm{PM}$, and $\mathrm{NO}_{2}$, which may lead to negative consequences for human health and the local environment. In addition, some articles on COVID-19 and its impacts on decreasing the level of public transportation usage, such as Chinazzi et al. [6], suggest that, at beginning of the travel restriction from Wuhan on 23 January, most Chinese cities had already received numerous infected travelers. In the case of air quality, Bontempi [17] described the correlation between air pollution and the spread of the virus, Abdullah et al. [18] considered that movement control regulations have significant effects on reducing the PM2.5 concentrations. Dantas et al. [19] assessed the impact of the partial lockdown imposed due to COVID-19 on the air quality of the city of Rio de Janeiro, Mahato et. al. [20] examined the air quality during the lockdown period with special reference to the megacity of Delhi, and Zoran et al. [21] assessed the relationship between surface levels of PM2.5 and PM10 during COVID-19 in Milan, Italy. As an initial phase in the review procedure, a summary of the existing literature related to COVID-19 and public transportation and the AQI is provided.

\subsection{Public transportation}

The evaluation performed via the TomTom application and published in the TomTom Traffic Index shows the traffic jam ranges in several cities all over the world. TomTom provides the traffic user with incredibly accurate traffic information in real-time. It is an application which can determine where the 
traffic is slowing down and why [22]. It discovered that present congestion ranges are under $10 \%$ due to the impact of the coronavirus, while common congestion ranges in these types of cities are usually around $50-70 \%$. Public transportation systems are the most affected by this decline, as a large number of passengers refrain from using different modes of public transportation in order to avoid social contact and reduce the risk of infection. Where travel restrictions have been enforced, the decrease in the number of trips was always higher percentage-wise for public transportation than for private transport. For instance, Delhi, India, or Wuhan, China, recorded a drop of $80-90 \%$ in the number of passengers $[22,23]$.

Motivated by the rapid spread of the coronavirus in mainland China, Chinazzi et al. [6] used a worldwide meta-population disease transmission model to consider the effect of travel restrictions on the spread of the disease at international and national scale. The result demonstrates that, at beginning of the travel suspension from Wuhan on 23 January, most Chinese cities had already received a large number of infected travelers. The travel quarantine of Wuhan postponed the overall epidemic development in mainland China by only 3 to 5 days; however, it had a more noticeable impact at international level, where the number of imported cases decreased by almost $80 \%$ by mid-February.

In a study conducted by Aloi et al. [9] it was found that the city of Bogotá, Colombia, carried out a simulation of travel restriction measures on 23 March, and the Trans Milenio (i.e. bus rapid transit (BRT) system) recorded a $87 \%$ drop in the number of passengers. A review by INRIX in Seattle, USA, using data from mid-March, discovered a decline in travel of up to $60 \%$ and improvements in travel times of $26 \%$, with a $13 \%$ drop in vehicles per kilometer. INRIX is a privately held company headquartered in Kirkland, Washington. It provides location-based data and analytics, such as traffic and parking, to automakers, cities, and road authorities worldwide, and in turn-by-turn navigation applications such as Google [24]. In addition, a worldwide evaluation of mobility recently published by Google [25] showed a global decline in travel in almost every country.

There are also several recommendations and guidelines-based reports published by official entities, for example, the International Organization for Public Transport Authorities and Operators [26], the Transportation Research Board [27], and the American Public Transport Association [28] to provide best practices for preparing and operating public transportation systems under health emergencies.

\subsection{Air quality pollution}

Air quality regulations have been applied in Turkey since 1986 . These guidelines include many comprehensive regulations governing emission limits for combustion systems and industrial activities. Currently, air quality requirements are hindering radical improvements by the Ministry of Environment in Turkey. This revision of the Turkish law includes $\mathrm{SO}_{2}, \mathrm{PM} 10, \mathrm{NO}_{2}$, and $\mathrm{CO}$ pollution limits at short and long-term average values. Turkish air quality protection regulations set short-term limits of $300 \mu \mathrm{g} / \mathrm{m}^{3}$ and $400 \mu \mathrm{g} / \mathrm{m}^{3}$ for $\mathrm{PM}$ and $\mathrm{SO}_{2}$, respectively, as well as a long-term limit value of $150 \mu \mathrm{g} / \mathrm{m}^{3}$ for both. Nevertheless, several Turkish cities have been found to have concentrations of these levels of air pollution which exceed these limits. National laws also require the urban air quality level during the 8-month winter period to be $200 \mu \mathrm{g} / \mathrm{m}^{3}$ for PM and $250 \mu \mathrm{g} / \mathrm{m}^{3}$ for $\mathrm{SO}_{2}$ [29].

Bontempi [17] examined the PM10 value in Lombardy, Italy, from the second week of February to the end of March, i.e., a few days before the healthcare emergency explosion. Information is collected for Bergamo, Brescia, Milano, Lodi, Cremona, Alessandria, Pavia (Lombardy), Monza-Brianza, Biella, Novara, Vercelli, Torino (Piedmont), and Asti. The results show that it is not possible to determine whether the coronavirus is also spread through the air, by using PM10 as a carrier. Specifically, it is demonstrated that Piedmont cities, which had a lower number of recognized infection cases compared to Bergamo and Brescia in the researched period, had the most severe PM10 pollution events compared to Lombardy cities. This first research may serve as a reference to better understand and anticipate the elements that influence the coronavirus spread and transmission routes, highlighting the role of air particulate matter in the atmosphere.

Abdullah et al. [18] considered the amount of the AQI during the Malaysia Movement Control Order (MCO) with the purpose of isolating the source of the coronavirus outbreak. They obtained the Air Pollutant Index (API) information from the Department of Environment of Malaysia prior to and in the course of the MCO with the purpose of tracking the variations of PM2.5 in 68 air quality monitoring 
areas. It was found that the PM2.5 concentrations showed a substantial decrease of up to $58.4 \%$ in the course of the MCO. The PM2.5 concentrations variation also decreased by up to $28.3 \%$ in many red zone locations. Abdullah et al. concluded that the decrease was not exclusively due to the MCO; therefore, experts recommend further research, taking into account the influencing elements that need to be considered in the future.

Bao and Zhang [1] used daily air pollution data and Intercity Migration Index (IMI) data from the Baidu company from 1 January until 21 March for 44 cities in the north of China to analyze how, whether, and to what extent travel limitations impacted the AQI. Based on this particular quantitative evaluation, Bao and Zhang concluded that the decrease in air pollution was highly related to the travel limitations in the course of this pandemic. On average, the AQI decreased by $7.80 \%$, and the concentration of five air pollutants, including $\mathrm{SO}_{2}$, decreased by $6.76 \%$, followed by PM2.5 $=5.93 \%$, $\mathrm{PM} 10=13.66 \%, \mathrm{NO}_{2}=24.67 \%$, and $\mathrm{CO}=4.58 \%$.

Dantas et al. [19] examined the impact of the measures on the air quality of the city by comparing the $\mathrm{PM}, \mathrm{CO}, \mathrm{NO}_{2}$, and $\mathrm{O} 3$ levels recorded during the partial lockdown with levels recorded during a similar period in 2019 and also with the weeks leading up to the COVID-19 outbreak. CO concentrations showed the most substantial reductions, i.e., around $30.3-48.5 \%$, since they were associated with light-duty vehicular emissions. The $\mathrm{NO}_{2}$ concentration showed reductions although the PM10 concentration decreased only in the first week of the lockdown. April saw an increase in the movement of vehicles and people, primarily due to the lack of an agreement on the extent and requirements of the lockdown and social distancing. The ozone level probably increased due to the reduction in $\mathrm{NO}_{2}$ concentration. Compared to a similar period in 2019, $\mathrm{CO}$ and $\mathrm{NO}_{2}$ median levels were $37.0-43.6 \%$ and 24.1-32.9\% lower. Meteorological interferences, primarily the transmission of pollutants from industrial areas, might have also influenced the outcomes.

Mahato et al. [20] evaluated the air quality scenario around the lockdown period in the megacity of Delhi, India. Using air quality information of seven pollutant variables for 34 monitoring stations distributed across this megacity, they used the National Air Quality Index (NAQI) to present the spatial structure of air quality before and in the course of lockdown stages. The outcomes confirmed that air quality improved significantly over the course of the lockdown. Among the chosen pollutants, levels of PM2.5 and PM10 showed the highest decrease in comparison to the pre-lockdown stage. Compared to last year (i.e. 2019), over the said period, the reduction in PM2.5 and PM10 is as high as about 39\% and $60 \%$, respectively. Among other pollutants, $\mathrm{CO}$ and $\mathrm{NO}_{2}$ concentrations also decreased in the course of the lockdown stage. Only four days after the start of the lockdown, an improvement in air quality of 50 to $40 \%$ was observed.

\section{MATERIAL AND METHOD}

\subsection{Case study}

This research analyzes the level of public transportation usage and the AQI during COVID-19 (from January 2020 until the end of May 2020) in two cities of Turkey, i.e., Ankara $\left(39.9334^{\circ} \mathrm{N}\right.$, $\left.32.8597^{\circ} \mathrm{E}\right)$ and Istanbul $\left(41.0082^{\circ} \mathrm{N}, 28.9784^{\circ} \mathrm{E}\right)$.

The AQI depends on five "criteria" pollutants regulated by the Clean Air Act, including ground-level $\mathrm{O}_{3}, \mathrm{PM}, \mathrm{CO}, \mathrm{SO}_{2}$, and $\mathrm{NO}_{2}$. The Environmental Protection Agency determined ambient air quality standards for each of these pollutants in order to protect public health. An AQI value of X, for example $\mathrm{AQI}=45$ (class I - green), typically corresponds to the level of the ambient air quality standards for the pollutant.

In order to assess the air quality status for Turkey (i.e. Ankara and Istanbul) during the pre-lockdown and lockdown period, data were collected manually from the World's Air Pollution map [30]. In this regard, raw data for each criterion, as mentioned above, were collected and analyzed by entering them into spreadsheets in the EXCEL software.

Ankara is the capital of Turkey and the second-largest city in Turkey after Istanbul. It is situated at the heart of both Turkey and Central Anatolia. The population is approximately 4.5 million. It is an inland city and the main business and administrative center of Turkey. Geographically, it is situated on a small plateau surrounded by the low hills of the northern Turkey highlands. Ankara is more suitable for urban mobility and transportation than Istanbul, including numerous options for city transportation. There are standard metro and minibus services as well as regular bus lines for quick access to several key areas of the city. 
Istanbul, with a population of around 15 million, is one of the largest cities in Europe and the world, situated on both sides of the Bosphorus (i.e. the narrow strait between the Marmara Sea and the Black Sea), which is a bridge between Asia and Europe. This city has a remarkable transportation system using nearly all recognized types of public transportation, including busses, metrobusses, trams, suburban trains, subway trains, cable cars, funiculars, sea taxis, sea busses, and fast ferries. Metrobus is a public vehicle that originates from the combination of metro and bus. It operates on dedicated lanes with rubber wheels. It can move quickly in traffic since it has its own special lane [31]. Cable car refers to a suspended vehicle that travels between two distant places by being attached to one or more steel ropes stretched in the air [32]. The average time people spend commuting by public transportation, for instance to and from work, during a working day is approximately $91 \mathrm{~min}$. Around $30 \%$ of passengers using public transportation travel for more than 2 hours every day.

There are massive public transportation systems in Turkey, including local busses, minibusses, taxis, the metro, and the tram. In all cities and towns there are numerous low-cost local busses. Passengers can buy a smart ticket for a small deposit, which can be used not only on the busses but also the tram, ferries, and the metro. Minibusses (Dolmus) are valuable alternatives to local busses and provide services on regular routes, which are displayed on the vehicle's windscreen. Taxis are numerous and they are mostly boarded at designated taxi stops. The price is based on the on-board meter, and all taxis in Turkey are required by law to have an on-board meter. Much more common, however, are fixed prices for intercity travel, which are determined at the taxi stop.

Turkey's metro system of overground and underground rapid transit is developing rapidly. The major cities in Turkey now have underground metros. Passengers are required to purchase a smart ticket to travel by metro. Railway transportation is one of the common systems in Turkey, especially in Ankara, Istanbul, Eskisehir, Izmir, Bursa, Antalya, etc. The city of Istanbul accounts for almost half of the rail passengers in urban transport, nearly 47.5 million every month. The city of Ankara follows with 10 million passengers, as shown in Figure 1. Eskisehir Tram (Estram), which won the UITP's 2004 rail award, has the greatest coverage, where each resident travels by rail almost 5 times a month. Ankara and Istanbul, as shown in Table 1, follow Eskisehir with around 3.4 and 2.0, respectively [33]. Another criterion is ridership per kilometer, as illustrated

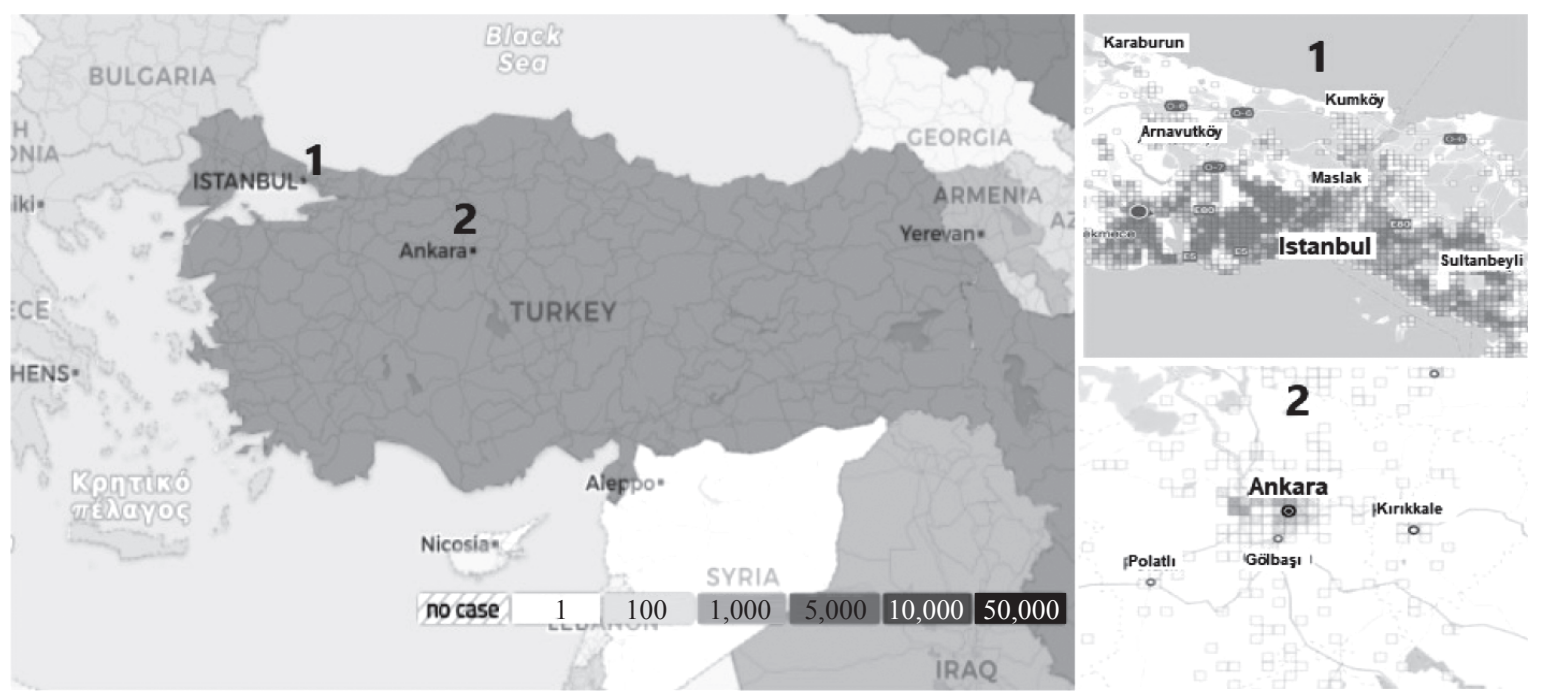

Figure 1 - Location of Ankara and Istanbul, Turkey

Table 1 - Monthly ridership of the railway system

\begin{tabular}{||c|c|c|c|}
\hline Cities & Monthly ridership (million) & Monthly ridership per population & $\begin{array}{c}\text { Monthly ridership / network } \\
\text { length }\end{array}$ \\
\hline \hline Istanbul & 47.5 & 3.4 & 343 \\
\hline Ankara & 10 & 2.0 & 108 \\
\hline
\end{tabular}

Source: [33] 
in Table 1, which may help us understand how effective the rail system is. Istanbul has the top value of around 343 monthly ridership per kilometer, followed by Ankara with a monthly ridership per kilometer that amounts to 108 .

As for the metro system, Turkey has 4 cities with metros. Istanbul offers the largest network in terms of ridership and length. In this case, the magnitude of the monthly ridership in Istanbul and Ankara metros is around 28.7 and 6.0 million, with a network length of almost 90.5 and 46.6 kilometers, respectively.

Light rail systems, unlike metro systems, are predominantly above ground with lower capacities. In this case, Ankara has around 330,000 passengers per kilometer. The monthly ridership and network length of the light rail system in Ankara is 2.8 million and 8 kilometers, respectively. In terms of monthly light rail ridership and network length, Ankara ranks second and third, respectively.

Trams are entirely above ground, occasionally using the same areas as vehicles, have the capability to run within streets and make sharp turns, as well as low capacity. Istanbul has the second largest tram network after Kayseri, with 2 lines and the largest ridership. The values of monthly ridership and network length are roughly 13.2 million and 33.8 kilometers, respectively. In Ankara, the monthly ridership amounts to almost 1.2 million, and the network length is around 11 kilometers.

Suburban lines are the urban service on the national rail network, which is provided specifically by or in cooperation with Turkish State Railways (TCDD). Istanbul, with a 14-kilometer network length, as the third city after Izmir and Ankara, has a monthly ridership of 4.6 million. In terms of suburban lines, Ankara has a monthly ridership of 1.1 million and a network length of 37 kilometers.

\subsection{METHOD}

Air pollution is a major risk element for health both in Europe and worldwide. A recent evaluation of the global coronavirus problem found it to be one of the top ten risk elements for human health throughout the world. The Organization for Economic Cooperation and Development (OECD) predicts that in 2050 outdoor air pollution will probably be the top cause of environmentally-related fatalities globally. Furthermore, air pollution is also categorized as the primary environmental cause of cancer [34].
The AQI is used by government agencies to demonstrate how polluted the air presently is and provides information on the long-term or short-term effect of air pollution on human health. To calculate the AQI, an air pollutant level over a specific period is needed, which is acquired from an air monitor or model. Taken together, the air pollutant levels and time indicate the number of air pollutants [35].

The daily AQIs are calculated based on the 24-hour average levels of $\mathrm{SO}_{2}, \mathrm{CO}, \mathrm{NO}_{2}, \mathrm{PM} 2.5$, PM10, and the highest daily 8-hour average level of $\mathrm{O}_{3}$. The AQI indicates the highest pollution sub-index of the aforementioned six individual pollutants' levels, i.e., using Equations 1 and 2. The higher value of the AQI is related to the lower air quality for that area. The air pollutant with the highest AQI value is then described as the main pollutant on that day $[36,37]$.

The ranges of AQI values associated with air quality can be categorized into six classes: $0-50$ (good, green), 51-100 (moderate, yellow), 101-150 (unhealthy for sensitive groups, orange), 151-200 (unhealthy, red), 201-300 (very unhealthy, purple), 301-500 (hazardous, maroon) [37]. More details about each class will be described in the next section.

$I=\frac{I_{\text {high }}-I_{\text {low }}}{C_{\text {high }}-C_{\text {low }}} \cdot\left(C-C_{\text {low }}\right)+I_{\text {low }}$

$A Q I=\max \left(I_{1}, I_{2}, \ldots, I_{n}\right)$

where, $I$ is the AQI, $C$ is the pollutant concentration, $C_{\text {low }}$ is the concentration breakpoint that is $\leq C, C_{\text {high }}$ is the concentration breakpoint that is $\geq C, I_{\text {low }}$ is the index breakpoint corresponding to $C_{l o w}, I_{h i g h}$ is the index breakpoint corresponding to $C_{\text {high }}$.

\section{RESULT AND DISCUSSION}

\subsection{Public transportation}

Due to the coronavirus, the number of passengers using public transportation has declined considerably in major cities worldwide. As residents of several countries begin to work from home, they tend to avoid public transportation in order to reduce exposure to the disease and they have changed the mode of travel within their cities due to the decrease in local public transportation services. The world's leading urban mobility services (MaaS) device as well as the first public transportation application Moovit [38] published a record on the impact of COVID-19 on public transportation, based on com- 
mon usage before the outbreak. Moovit's Trends, modified daily, display the different shares of public transportation requirements throughout the world, in accordance with common usage during the lockdown and also before the lockdown. The information is based on an evaluation of the effective ranges of 750 million Moovit users [39].

In Turkey, Moovit examined the public transportation usage in cities such as Istanbul and Ankara, and analyzed the number of passengers. For example, although the number of public transportation passengers in Ankara rose to almost 20\% before 11 March, it dramatically decreased by $82 \%$ by the end of March because of the COVID-19 pandemic. Similarly, in Istanbul this percentage rose by $11.5 \%$ before the lockdown announcement, while public transportation usage suddenly decreased by $80.5 \%$. As shown in Figure 2, these percentages changed from decreasing to a steady-state by 11 May, which was the end of lockdown in Turkey. After this time, although some public areas were opened, the use of public transportation did not change significantly until the end of May.

This decline in usage in Ankara and Istanbul is due to both the reluctance of passengers themselves and the recommendations of health authorities in Turkey to avoid the use of public transportation as much as possible, suggesting the use of individual means of transport such as bicycles. Regardless of such recommendations, researchers and experts have been considering the risk of contagion related to the use of shared bicycle systems [9].

Regarding the public transportation trend as shown in Figure 2, some interesting facts about the number of people using different types of public transportation before and during the lockdown in Ankara are provided in Table 2. Before the lockdown announcement, the number of people who used busses, public transportation (except the bus), the metro, and the light rail system was around 243,938, $124,512,363,151$, and 123,756, respectively. In contrast, because of the COVID-19 pandemic and the lockdown announcement, these figures dramatically decreased to $54,260,81,258,187,378$, and 61,632 , respectively.

Table 3 illustrates the number of people using different means of public transportation from January until May in Istanbul. In the light of the lockdown announcement of 11 March, the number of public transport usage for seaway, the Marmaray, metrobus, metro-tram, and bus regularly decreased to more than $3,7,15,35$, and 60 million passengers, respectively. In addition, during April, the use of the aforesaid public transportation modes dropped significantly, i.e., by more than $80 \%$.

Table 2 - Number of people using public transportation before and during the lockdown in Ankara

\begin{tabular}{||l|c|c||}
\hline \multicolumn{1}{|c|}{$\begin{array}{c}\text { Type of public } \\
\text { transportation }\end{array}$} & $\begin{array}{c}\text { Before } \\
\text { lockdown }\end{array}$ & $\begin{array}{c}\text { During } \\
\text { lockdown }\end{array}$ \\
\hline \hline Busses & 243,938 & 54,260 \\
\hline $\begin{array}{l}\text { Public transportation } \\
\text { (without bus) }\end{array}$ & 124,512 & 81,258 \\
\hline Metro & 363,151 & 187,378 \\
\hline Light rail system & 123,756 & 61,632 \\
\hline $\begin{array}{l}\text { Other means of public } \\
\text { transportation }\end{array}$ & 796,294 & 515,294 \\
\hline $\begin{array}{l}\text { Total usage of public } \\
\text { transportation }\end{array}$ & $1,651,651$ & 899,822 \\
\hline
\end{tabular}

Source: [40]

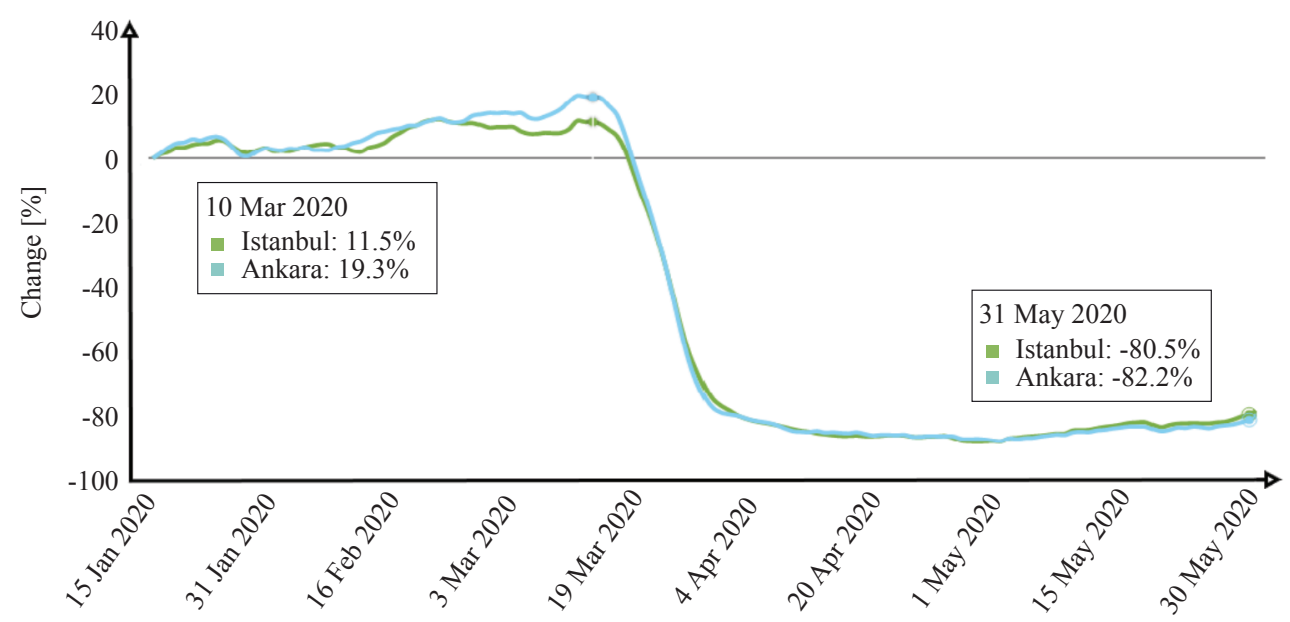

Figure 2 - Analysis of public transportation usage from January (source: www.moovit.com) 
Sahraei MA, Kuşkapan E, Çodur MY. Impact of Covid-19 on Public Transportation Usage and Ambient Air Quality in Turkey

Table 3 - Number of people using different means of public transportation during January-May in Istanbul

\begin{tabular}{||l|c|c|c|c|c||}
\hline \multicolumn{1}{|c|}{$\begin{array}{c}\text { Type of public } \\
\text { transportation }\end{array}$} & January & February & March & April & May \\
\hline \hline Seaway & $5,774,980$ & $5,769,773$ & $3,789,784$ & 405,339 & 579,889 \\
\hline $\begin{array}{l}\text { Marmaray } \\
\text { Commuter rail) }\end{array}$ & $12,612,183$ & $12,318,223$ & $7,586,214$ & $1,223,373$ & $1,624,104$ \\
\hline $\begin{array}{l}\text { Metrobus } \\
\text { (type of bus system) }\end{array}$ & $24,959,315$ & $24,487,078$ & $15,792,992$ & $2,710,667$ & $3,683,836$ \\
\hline Metro-tram & $59,262,293$ & $57,560,079$ & $35,499,609$ & $5,347,396$ & $7,103,310$ \\
\hline Bus & $93,116,072$ & $92,535,434$ & $60,553,291$ & $12,257,750$ & $14,615,702$ \\
\hline Total & $195,724,843$ & $192,670,587$ & $123,221,890$ & $21,944,525$ & $27,606,841$ \\
\hline
\end{tabular}

Source: [40]

This was due to the government guidelines and regulations to minimize the use of public areas as well as the use of public transportation. When COVID-19 was found in Turkey, the TCDD announced that its trains are being disinfected every day [3]. In addition, the Turkish railway authority announced that all intercity trains would be suspended, and the mayor of Istanbul reiterated that the nostalgic tram from the central Taksim Square along the pedestrian Istiklal Street would be suspended. Domestic flights by Turkish Airlines would only operate from Istanbul and Ankara to certain major cities.

With many people working from home or staying home, the decrease in vehicle emissions is likely to be a positive outcome of the COVID-19 pandemic, even if it is short-term. The temporary halt in vehicle emissions in the course of the lockdown provides a unique opportunity to evaluate the effect of driving on air quality [41]. The effect of the COVID-19 pandemic on the AQI will be described in the following section.

\subsection{Air Quality Index}

The AQI is an evaluation of how air pollution impacts one's health during a specific period. The goal of the AQI is to help people understand how the local air quality affects their health. The AQI is divided into six groups, and each group corresponds to a specific level of health concern. Each group also has a specific color that makes it easy for a person to identify whether the air quality in their community is reaching unhealthy levels.

1) Class I, good, $0-50$ (green), the air quality is satisfactory, and air pollution poses little or no risk.
2) Class II, moderate, 51-100 (yellow), the air quality is acceptable. However, there may be a risk for some people, particularly those who are unusually sensitive to air pollution.

3) Class III, unhealthy for sensitive groups, 101150 (orange), members of sensitive groups may experience health effects. The general public is less likely to be affected.

4) Class IV, unhealthy, 151-200 (red), some members of the general public may experience health effects; members of sensitive groups may experience more serious health effects.

5) Class V, very unhealthy, 201-300 (purple), health alert: the risk of health effects is increased for everyone.

6) Class VI, hazardous, 301 and higher (maroon), health warning of emergency conditions: everyone is more likely to be affected.

Figures 3 and 4 show the percentage of AQI classes from January until the end of May 2019 and 2020 in Ankara and Istanbul. In Ankara, as shown in Figure 3, the daily AQI (2019) for classes I, II, III, IV, V, and VI was 0, 76-93, 104-149, 151-200, 204-238, and 0 , respectively. Based on these values, the percentages of the AQI for these classes were estimated at around $0.00 \%, 4.64 \%, 31.79 \%, 60.93 \%, 2.65 \%$, and $0.00 \%$, respectively. In 2020, the daily AQI for classes I, II, III, IV, V, and VI was 0, 57-99, 102146, 151-193, 204-297, and 316-366, respectively. Consequently, the percentages of the AQI for these classes were estimated at around $0.00 \%, 13.82 \%$, $23.03 \%, 49.34 \%, 11.84 \%$, and $1.97 \%$, respectively.

In Istanbul, the daily AQI (2019) for classes I, II, III, IV, V, and VI, as shown in Figure 4, was 0, 86-97, 109-131, 152-193, 204-297, and 306-349, respectively. Based on these values, the percentages of the AQI for these classes were around $0.00 \%, 1.32 \%$, 


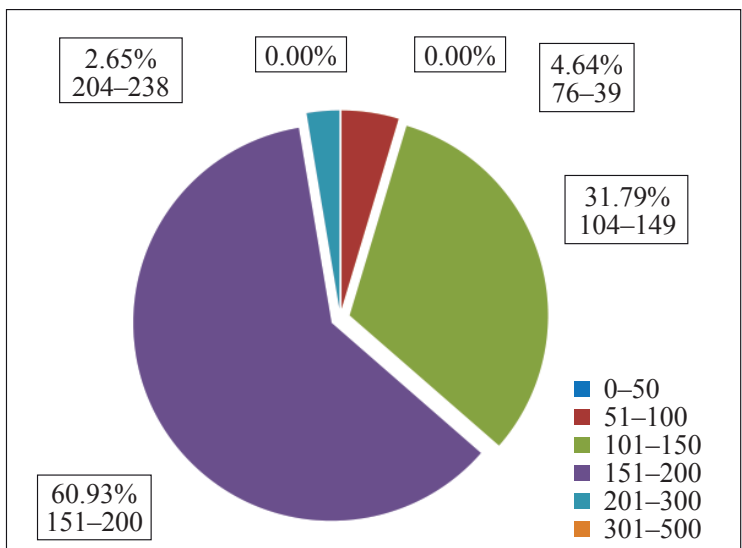

a) 2019

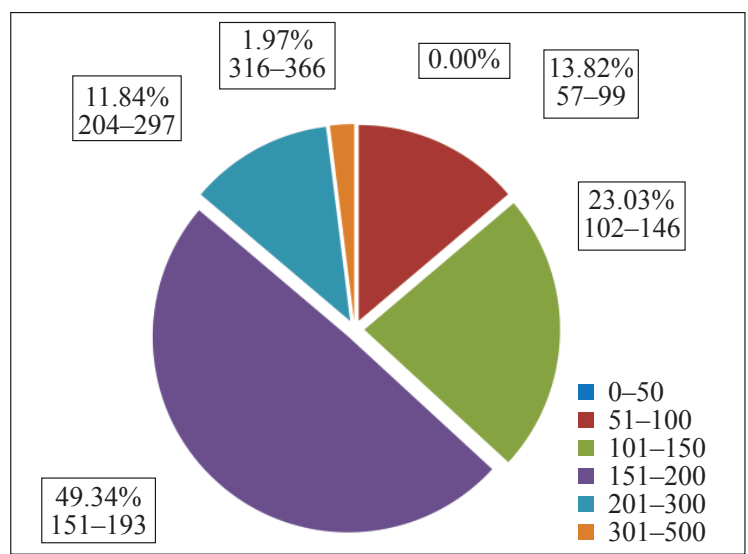

b) 2020

Figure 3 - Percentage of AQI classes during January-May in Ankara

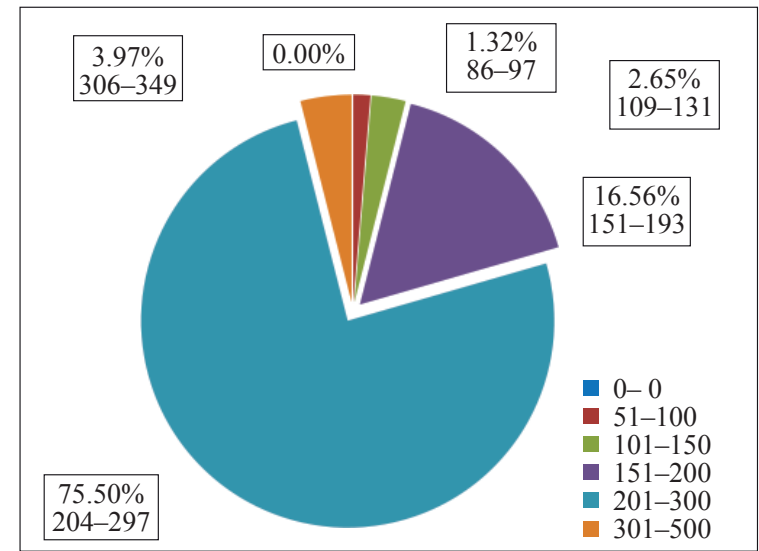

a) 2019

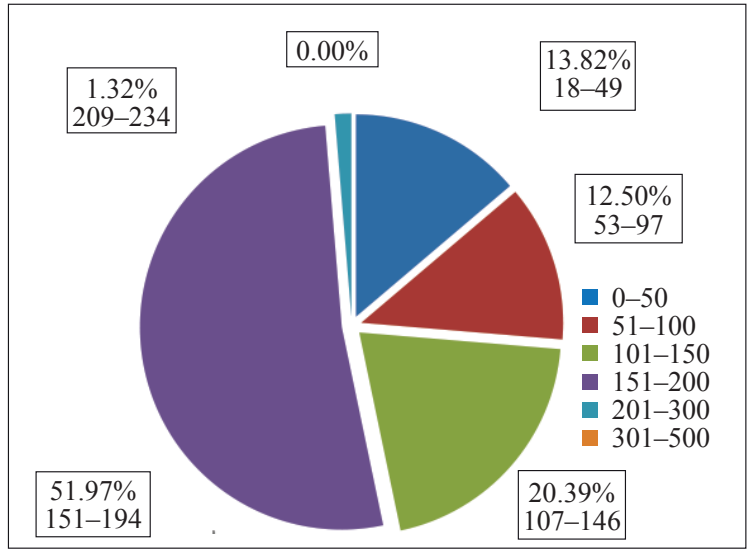

b) 2020

Figure 4 - Percentage of AQI classes during January-May in Istanbul

$2.65 \%, 16.56 \%, 75.50 \%$, and $3.97 \%$, respectively. In 2020, the daily AQI for classes I, II, III, IV, V, and VI was 18-49, 53-97, 107-146, 151-194, 209-236, and 0 , respectively. Consequently, the percentages of the AQI for these classes were approximately $13.82 \%, 12.50 \%, 20.39 \%, 51.97 \%, 1.32 \%$, and $0.00 \%$, respectively. The air pollution indicators used to estimate the AQI values for both cities in 2019 and 2020 were PM2.5, PM10, $\mathrm{O}_{3}, \mathrm{NO}_{2}, \mathrm{SO}_{2}$, and $\mathrm{CO}$.

Table 4 shows the comparison of AQI values in Ankara and Istanbul from January until the end of May for 2019 and 2020. In Ankara (2019), the number of days for classes I, II, III, IV, V, and VI were 0 , $7,48,92,4$, and 0 , respectively, while in 2020 they were $0,21,35,75,18$, and 3 , respectively. Accordingly, the number of days in 2019 for classes III (unhealthy for sensitive groups) and IV (unhealthy) was higher than in 2020. In Istanbul (2019), the number of days for classes I, II, III, IV, V, and VI were 0,2 , $4,25,114$, and 6 , while in 2020 they were 21,19 , $31,79,2$, and 0 , respectively. Although the number
Table 4 - Comparison of AQI values from January until the end of May

\begin{tabular}{||c|c|c|c|c||}
\hline \multirow{3}{*}{ AQI category } & \multicolumn{2}{|c|}{ Ankara } & \multicolumn{2}{c||}{ Istanbul } \\
\cline { 2 - 5 } & 2019 & 2020 & 2019 & 2020 \\
\cline { 2 - 5 } & Day & Day & Day & Day \\
\hline \hline Class I (0-50) & 0 & 0 & 0 & 21 \\
\hline Class II (51-100) & 7 & 21 & 2 & 19 \\
\hline Class III (101-150) & 48 & 35 & 4 & 31 \\
\hline Class IV (151-200) & 92 & 75 & 25 & 79 \\
\hline Class V (201-300) & 4 & 18 & 114 & 2 \\
\hline Class VI (301-500) & 0 & 3 & 6 & 0 \\
\hline
\end{tabular}

of days for class I (good), class II (moderate), class III (unhealthy for sensitive groups), and class IV (unhealthy) was higher in 2020 than in 2019, classes V (very unhealthy) and VI (hazardous) had much higher figures in 2019 than they did in 2020.

Figure 5 shows the level of the AQI value for Ankara and Istanbul from January until the end of May. To begin, in Ankara, the AQI value in January 2020 was higher than in 2019 until about the first week 


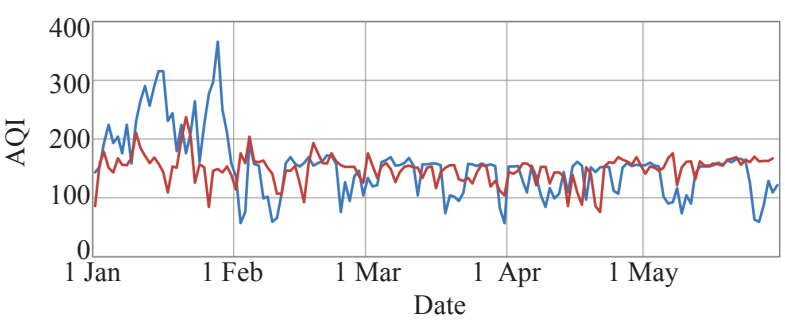

a) Ankara

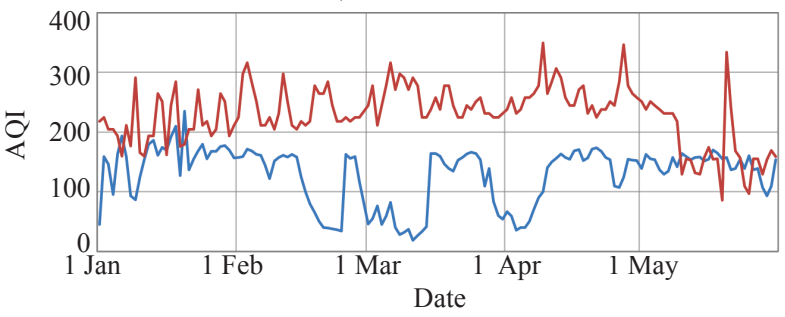

b) Istanbul

- AQI $2020-$ AQI 2019

Figure 5 - Air Quality Index (AQI) value

of February, and this remained so throughout that period. Since then, it plummeted to around 50 and has fluctuated between around 50 and 150 until the end of May 2020. In contrast, the AQI value in 2019 fluctuated between roughly 100 and 200 and was mostly estimated to be higher than the AQI in 2020.

In Istanbul, the AQI value was estimated to be around 50 the first day of January 2020 and then rose to approximately more than 350 , while it dramatically decreased to 50 in the first week of February. The cause of this decrease in the AQI value is the COVID-19 pandemic around the world and also Turkey, which led to a reduction of traffic in urban areas and the reduction of industrial activities. In addition, after the first death due to the aforementioned disease occurred in the country on 15 March 2020, the government imposed further restrictions regarding the use of public transportation. For this reason, the values of the AQI dramatically decreased to 35 in the first week of April.
This lasted until March, when the Turkish Minister of Industry and Technology announced that on 11 May almost all major automotive factories in Turkey would resume operations. Describing the new stage with relaxed restrictions as "controlled social life", the Turkish government noted that the outbreak in the country was now under control, but the danger remains, and citizens must not give up on the measures. As can be seen in Figure 5, the AQI increased to around 150 on 11 March 2020 and remained at an approximately higher value than the AQI in 2019.

Table 5 shows the comparison of AQI values during the lockdown in Ankara and Istanbul in 2020 and the same date in 2019. As described above, the lockdown imposed due to the coronavirus in Turkey was announced for the period from 16 March until 11 May 2020, i.e., 57 days. As shown in Table 5, during the lockdown in Ankara, the percentages of the AQI for classes I, II, III, IV, V, and VI were calculated at around $0.00 \%, 19.30 \%, 29.82 \%, 50.88 \%$, $0.00 \%$, and $0.00 \%$, respectively. Accordingly, the number of days associated with each class was 0 , $11,17,29,0$, and 0 , respectively. In Istanbul, the percentages of the AQI during the lockdown for classes I, II, III, IV, V, and VI were calculated at around $7.02 \%, 14.04 \%, 26.32 \%, 52.63 \%, 0.00 \%$, and $0.00 \%$, respectively. In this case, the number of days related to each class was $4,8,15,30,0$, and 0 , respectively. When comparing data for the city of Ankara between the lockdown period of 2020 and the same date in 2019, as shown in Table 5, it is evident that the percentages of the AQI (2020) in class II were significantly higher than in 2019. In addition, in Istanbul, the share of classes I, II, and III (2020) was higher than in 2019.

The above descriptions show that the air quality in Ankara and Istanbul in 2020 (from January until the end of May), especially during lockdown days,

Table 5 - Comparison of AQI values during the lockdown in 2020 and the same date in 2019

\begin{tabular}{||c|c|c|c|c|c|c|c|c||}
\hline \multirow{2}{*}{$\begin{array}{c}\text { AQI } \\
\text { category }\end{array}$} & \multicolumn{4}{|c|}{ Ankara } & \multicolumn{4}{c||}{ Istanbul } \\
\cline { 2 - 10 } & 2019 (same date) & 2020 (lockdown) & 2019 (same date) & \multicolumn{2}{c|}{2020 (lockdown) } \\
\cline { 2 - 10 } & Day & Percentage & Day & Percentage & Day & Percentage & Day & Percentage \\
\hline \hline $0-50$ & 0 & 0.00 & 0 & 0.00 & 0 & 0.00 & 4 & 7.02 \\
\hline $51-100$ & 4 & 7.02 & 11 & 19.30 & 0 & 0.00 & 8 & 14.04 \\
\hline $101-150$ & 25 & 43.86 & 17 & 29.82 & 1 & 1.75 & 15 & 26.32 \\
\hline $151-200$ & 28 & 49.12 & 29 & 50.88 & 1 & 1.75 & 30 & 52.63 \\
\hline $201-300$ & 0 & 0.00 & 0 & 0.00 & 52 & 91.23 & 0 & 0.00 \\
\hline $301-500$ & 0 & 0.00 & 0 & 0.00 & 3 & 5.26 & 0 & 0.00 \\
\hline
\end{tabular}


was significantly better than during the same period of 2019. The reason was the COVID-19 pandemic and the specific restrictions imposed by the Turkish government regarding the use of public transportation.

\subsection{Policy management}

The Turkish government announced that the number of active cases is now decreasing, as is the number of patients requiring intensive treatment and medical ventilators, while the number of recovered patients is increasing significantly. The government indicated that the return to regular life would be slow and it set the rules for the gradual expansion of restrictions to be imposed in several steps in June and July. The details of this normalization procedure were as follows:

1) Persons over the age of 65 can only go out on one day of the curfew and only for 4 hours.

2) Persons in the 15-20 age group are allowed to go out between 11:00 am and 3:00 pm on Friday, 15 May, respecting the social distancing rules.

3) Young children up to the age of 14 can go out on 13 May from 11:00 am to 3:00 pm while adhering to measures of social distancing.

4) Assuming compliance with the regulations, shopping malls will begin to work on 11 May.

5) The city entry-exit restriction will be terminated for Erzurum, Aydın, Antalya, Mersin, Malatya, Hatay, and Muğla.

6) The military discharge processes will start on 31 May.

7) The High School Entrance Exam (LGS) will be organized on 20 June, and the Higher Education Institutions Exam (YKS) will be organized on 27-28 June.

8) Beauty salons, hairdressing salons, barbershops, etc. will open on 11 May.

9) On 5 May, the guidelines for even and odd license plate numbers introduced to restrict mobility across the cities will be terminated for commercial taxis in Izmir, Ankara, and Istanbul.

\section{CONCLUSION}

This research examines the impact of the COVID-19 pandemic on public transportation usage and ambient air quality in Ankara and Istanbul, Turkey. Data from public transportation applications Moovit and World's Air Pollution were collected and analyzed. The results of this research indicate that the percentage of public transportation usage for Ankara and Istanbul increased up to 19\% and $11 \%$, respectively before lockdown (i.e. 16 March), while it suddenly decreased by more than $80.5 \%$ when the Turkish government published its announcement. These percentages changed from decreasing to remaining the same until 11 May, which marked the end of the lockdown in Turkey. After this time, although some public areas were opened, the use of public transportation did not change significantly until end of May. This decline in usage in Ankara and Istanbul is due to both the reluctance of passengers themselves and the recommendations of health authorities in Turkey to avoid the use of public transportation as much as possible, suggesting the use of individual means of transport such as bicycles. In terms of the AQI level during the lockdown in Ankara, the minimum and maximum AQI level was estimated to be around 57 and 161, while in 2019, it was roughly 76 and 176, respectively. In Istanbul, the lowest and highest AQI value throughout lockdown was calculated at almost 35 and 173, while in 2019, it was around 129 and 349, respectively. When comparing the figures for the city of Ankara in 2020 (lockdown) and 2019 (the same date as the lockdown), the percentages of AQI (2020) in class II were estimated to be much higher than in 2019. In addition, in Istanbul, the proportion of classes I, II, and III (2020) was calculated to be much higher than that in 2019. In general, it is clear that in 2020, the ambient air quality in Ankara and Istanbul improved by around 9\% and $47 \%$, respectively. The reason was the COVID-19 pandemic and the specific restrictions imposed by the Turkish government regarding the use of public transportation. The government in Turkey considered increasing precautionary actions, such as a ban on private vehicles during the lockdown in cities, to reduce the spread of COVID-19. These restrictions nevertheless encouraged people to walk and bike, and to use public transportation only when necessary, to follow the social contact rules, wear a face covering and sanitize their hands. Since the results of this research showed that the lockdowns have led to a drastic decrease in the movement of people and the use of public transportation of up to $-90 \%$ by the end of May, it demonstrated that there is a link between public transportation usage and the improvement of air quality in Turkey during the lockdown. As for future research, the situations in other countries with high levels of COVID-19 exposure such 
as Italy, Spain, France, the United Kingdom (UK), Brazil, India, Russia, Colombia, etc. must be evaluated to examine the public transportation usage and the ambient air quality.
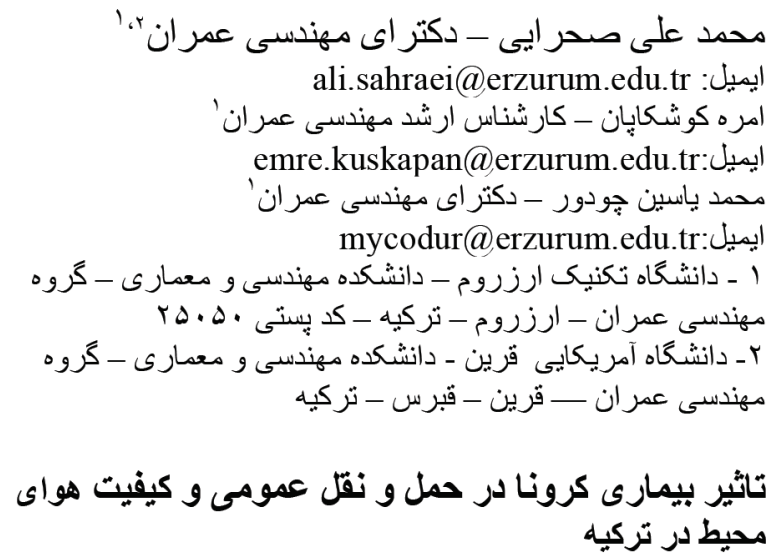

خلاصه مقاله

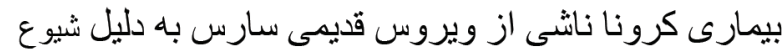

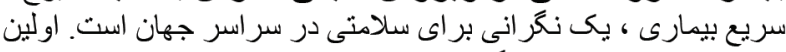

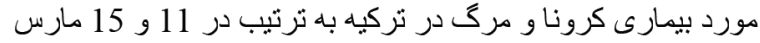

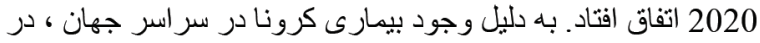

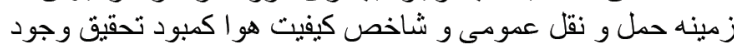

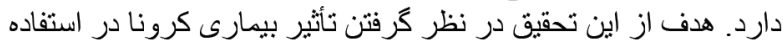

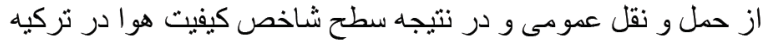

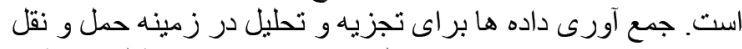

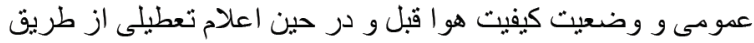

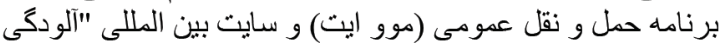

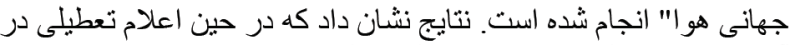

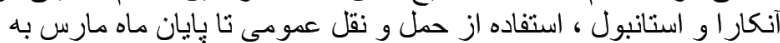

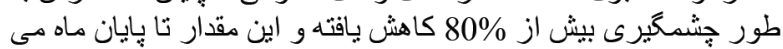

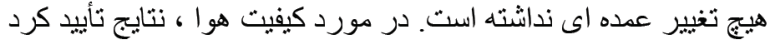

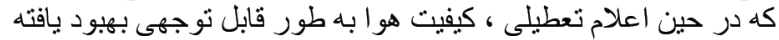

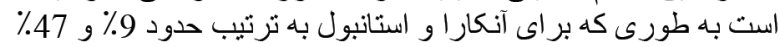

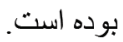
كلمات كليدى: بيمارى كرونا، حمل و نفل عمودى، شاخص كيفيت هو ا، تركيه، اعلام تعطيلى بلى بلى كرونا،

\section{REFERENCES}

[1] Bao R, Zhang A.Does lockdown reduce air pollution? Evidence from 44 cities in northern China. Science of The Total Environment. 2020;731: 139052.

[2] Tian $\mathrm{H}$, et al. An investigation of transmission control measures during the first 50 days of the COVID-19 epidemic in China. Science. 2020;368(6491): 638-642.

[3] Dailysabah. Turkey remains firm, calm as first coronavirus case confirmed; 2020. Available from: https://www.dailysabah.com/turkey/turkey-remainsfirm-calm-as-first-coronavirus-case-confirmed/news

[4] Quinn C. Turkey's Coronavirus Crisis Grows as Infections Exceed China's; 2020. Available from: https:// foreignpolicy.com/2020/04/20/turkeys-coronaviruscrisis-grows-as-infections-exceed-chinas/

[5] Anzai A, et al. Assessing the impact of reduced travel on exportation dynamics of novel coronavirus infection
(COVID-19). Journal of Clinical Medicine. 2020;9(2): 601.

[6] Chinazzi M, et al. The effect of travel restrictions on the spread of the 2019 novel coronavirus (COVID-19) outbreak. Science. 2020;368(6489): 395-400.

[7] Fan C, et al. The relationship between the migrant population's migration network and the risk of COVID-19 transmission in China-Empirical analysis and prediction in prefecture-level cities. International Journal of Environmental Research and Public Health. 2020;17(8): 2630.

[8] Kraemer MU, et al. The effect of human mobility and control measures on the COVID-19 epidemic in China. Science. 2020;368(6490): 493-497.

[9] Aloi A, et al. Effects of the COVID-19 Lockdown on Urban Mobility: Empirical Evidence from the City of Santander (Spain). Sustainability. 2020;12(9): 3870.

[10] WHO. Ambient (outdoor) air pollution in cities database 2014; 2014. Available from: https://www.who.int/phe/ health_topics/outdoorair/databases/cities-2014/en/

[11] WHO. Air pollution; 2019. Available from: https://www. who.int/health-topics/air-pollution\#tab=tab_1

[12] Wang H, et al. Trends in vehicular emissions in China's mega cities from 1995 to 2005. Environmental Pollution. 2010;158(2): 394-400

[13] Gulia S, et al. Urban air quality management-A review. Atmospheric Pollution Research. 2015;6(2): 286-304.

[14] Kandlikar M. Air pollution at a hotspot location in Delhi: detecting trends, seasonal cycles and oscillations. Atmospheric Environment. 2007;41(28): 5934-5947.

[15] Zambrano-Monserrate MA, RuanoMA, Sanchez-Alcalde L. Indirect effects of COVID-19 on the environment. Science of The Total Environment. 2020;728: 138813.

[16] ESA. COVID-19: nitrogen dioxide over China; 2020. Available from: https://www.esa.int/Applications/Observing_the_Earth/Copernicus/Sentinel-5P/COVID-19 nitrogen_dioxide_over_China

[17] Bontempi E. First data analysis about possible COVID-19 virus airborne diffusion due to air particulate matter (PM): The case of Lombardy (Italy). Environmental Research. 2020;186: 109639.

[18] Abdullah S, et al. Air quality status during 2020 Malaysia Movement Control Order (MCO) due to 2019 novel coronavirus (2019-nCoV) pandemic. Science of The Total Environment. 2020;729: 139022.

[19] Dantas G, et al. The impact of COVID-19 partial lockdown on the air quality of the city of Rio de Janeiro, Brazil. Science of The Total Environment. 2020;729: 139085.

[20] Mahato S, Pal S, Ghosh KG.Effect of lockdown amid COVID-19 pandemic on air quality of the megacity Delhi, India. Science of The Total Environment. 2020;730: 139086

[21] Zoran MA, et al. Assessing the relationship between surface levels of PM2. 5 and PM10 particulate matter impact on COVID-19 in Milan, Italy. Science of The Total Environment. 2020;738: 139825.

[22] TUMI. The COVID-19 outbreak and implications to sustainable urban mobility - some observations; 2020. Available from: https://www.transformative-mobility. org/news/the-covid-19-outbreak-and-implications-topublic-transport-some-observations

[23] Tom Tom. Traffic index ranking; 2020. Available from: 
https://www.tomtom.com/en_gb/traffic-index/ranking/

[24] INRIX. Understanding the Impact of COVID-19 on Commuting and Retail: An Analysis of the U.S. Epicenter 2020; 2020. Available from: https://inrix.com/campaigns/coronavirus-impact-study/

[25] Google. COVID-19 community mobility reports; 2020. Available from: https://www.google.com/covid19/mobility/index.html?hl=en

[26] UITP. The coronavirus and the public transport sector: UITP issues factsheet on management of outbreak; 2020. Available from: https://www.uitp.org/news/coronavirus-outbreak-uitp-and-public-transport-sector

[27] TRB. Transportation Research Board; 2020. Available from: https://www.nationalacademies.org/trb/transportation-research-board

[28] APTA. American Public Transportation Association; 2020. Available from: https://www.apta.com/

[29] Elbir T, Müezzinoğlu A, Bayram A.Evaluation of some air pollution indicators in Turkey. Environment International. 2000;26(1-2): 5-10.

[30] World's Air Pollution. Real-time Air Quality Index; 2020. Available from: https://waqi.info/\#/c/39.126/33.728/5z

[31] Rayhaber. Metrobüs Nedir? (English: What is Metrobus?); 2020. Available from: https://rayhaber. com/2020/01/metrobus-nedir/

[32] TopragizBiz. Teleferik Nedir? Nasıl Çalışır? (English: What is a ropeway? How does it work?); 2015. Available from: https://www.topragizbiz.com/konular/teleferik-nedir-nasil-calisir.4979/

[33] Uysal O. Best rail solutions in Turkish cities. Turkish Railway Journal and Review. 11 Nov. 2015. Available from: https://railturkey.org/2015/11/11/best-rail-solutions- in-turkish-cities/

[34] Marchal V, et al. OECD environmental outlook to 2050. Organization for Economic Co-operation and Development. 2011;8: 397-413.

[35] EPA. Risk Assessment; 2020. Available from: https:// www.epa.gov/risk

[36] She Q, et al. Air quality and its response to satellite-derived urban form in the Yangtze River Delta, China. Ecological Indicators. 2017;75: 297-306.

[37] $\mathrm{Xu} \mathrm{K}$, et al. Air Quality Index, Indicatory Air Pollutants and Impact of COVID-19 Event on the Air Quality near Central China. Aerosol and Air Quality Research. 2020;20.

[38] Moovit. Impact of Coronavirus (COVID-19) on Public Transit usage; 2020. Available from: https://moovitapp. com/insights/en/Moovit_Insights_Public_Transit_Index_Italy_Venezia-2083

[39] Raillynews. Coronavirus Effect of Number of Passengers in Public Transportation in Turkey; 2020. Available from: https://www.raillynews.com/2020/03/turkiyede-coronavirus-public-transportation-Amedaki-effect-on-the-number-of-passengers/

[40] Trthaber. Ankara'da toplu ulaşıma koronavirüs etkisi (English: Coronavirus effect on public transportation in Ankara); 2020. Available from: https://www.trthaber. com/haber/turkiye/ankarada-toplu-ulasima-koronavirus-etkisi-467759.html

[41] Medicalnewstoday. The dual effects of COVID-19 lockdowns on air quality; 2020. Available from: https://www. medicalnewstoday.com/articles/the-dual-effects-ofcovid-19-lockdowns-on-air-quality\#The-first-paper:-Nitrogen-dioxide 